\title{
Proximate mechanisms determining size variability in natterjack toads
}

\author{
U. Sinsch ${ }^{1}$, F. Marangoni ${ }^{2 \times}$, N. Oromi ${ }^{3}$, C. Leskovar ${ }^{1}$, D. Sanuy ${ }^{2} \&$ M. Tejedo ${ }^{3}$ \\ 1 Department of Biology, Institute of Integrated Sciences, University of Koblenz-Landau, Koblenz, Germany \\ 2 Department of Evolutionary Ecology, Estación Biológica de Doñana, CSIC, Sevilla, Spain \\ 3 Escola Técnica Superior Énginyeria Agrária, Departament Producció Animal (Fauna Silvestre), University of Lleida, Lleida, Spain
}

Keywords

amphibia; Anura; Bergmann's rule; life-history

traits; age at maturity; longevity; potential

reproductive lifespan; skeletochronology.

\section{Correspondence}

Ulrich Sinsch, Department of Biology, Institute of Integrated Sciences, University

of Koblenz-Landau, Universitätsstr. 1,

D-56070 Koblenz, Germany.

Email: sinsch@uni-koblenz.de

${ }^{\times}$Current address: FCEQyN, Universidad Nacional de Misiones, Consejo Nacional de Investigaciones Científicas y Técnicas, Félix de Azara 1552, 3300 Posadas, Argentina.

Editor: Tim Halliday

Received 15 December 2009; revised 17 February 2010; accepted 17 February 2010

doi:10.1111/j.1469-7998.2010.00702.x

\begin{abstract}
In the toad Bufo calamita, among-population variation of size follows roughly a converse Bergmann cline, but populations exist that do not fit this pattern. We propose that latitudinal body size variation is a byproduct of adaptive covariation among the life-history traits juvenile growth rate, longevity and lifetime fecundity. We choose five populations (two in Andalusia, two in Catalonia and one in Rhineland-Palatinate) representing a variation of adult size from $39 \mathrm{~mm}$ to $95 \mathrm{~mm}$ snout-vent length, a latitudinal gradient from 37 to 501 and an altitudinal gradient from sea level to $420 \mathrm{~m}$. Skeletochronology was used to estimate the age-related life-history traits of 313 toads and their lifetime pattern of growth. At southern latitudes, toads matured and reproduced earlier than those at northern latitudes, but had a reduced potential reproductive lifespan due to lower longevity. Ageadjusted adult size depended mainly on the size achieved between metamorphosis and first hibernation or aestivation, which in turn was influenced by local factors. We propose that first-year size corresponds to the duration of the aboveground activity period, temperature during the activity period and the type of shelter sites and hibernacula available in the habitat. After attaining sexual maturity, the growth rates did not differ among populations. Interactions of multiple environmental factors during the first year of life determine age at maturity, adult size and size variation among populations. Local body size and potential reproductive lifespan covary to optimize lifetime fecundity throughout the geographical range. The presence of a small-sized population in southern Spain does not fit the pattern predicted by a converse Bergmann cline, but is compatible with the hypothesis that body size variation among $B$. calamita populations may be the evolutionary byproduct of optimized lifetime fecundity.
\end{abstract}

\section{Introduction}

The body size of mammal and bird species often increases from a warm to a cool climate, that is from low to high latitudes and/or altitudes (Bergmann, 1847; Freckleton, Harvey \& Pagel, 2003; Meiri \& Dayan, 2003). This trend, known as Bergmann's rule, also holds for the intraspecific body size variation in the majority of endotherms (Ashton, 2002a; Meiri \& Dayan, 2003). Ray (1960) first proposed that the latitudinal size variation of ectotherms follows the same trend. However, there is considerable controversy about the general presence and direction of latitudinal clines and the underlying mechanisms in amphibians at the intra- and interspecific level (Ashton, 2002b; Krizmanic, Vukov \& Kalezic, 2005; Laugen et al., 2005; Olalla-Tarraga \& Rodriguez, 2007; Adams \& Church, 2008; Cvetkovic et al., 2009). Plethodon salamanders exemplify the case: body size was significantly related to the mean annual temperature in only 10 out of 40 species, three negatively and seven positively 272
(Adams \& Church, 2008). Moreover, regional body size clines may be present as in the frog Rana temporaria (Elmberg, 1991; Miaud, Guyetant \& Elmberg, 1999), but taking into account larger latitudinal gradients, a concave pattern of variation arises as the result of interactions among age effects, phenotypic plasticity and genetic determination (Laugen et al., 2005). Consequently, geographical size variation in amphibian species seems to have multiple causes, which may differ from the ecological, physiological and evolutionary explanations proposed for other tetrapods (e.g. heat balance hypothesis, migration ability hypothesis) and also between the interspecific and intraspecific level (Olalla-Tarraga \& Rodriguez, 2007; Adams \& Church, 2008; Gaston, 2008). Comprehensive case studies of the proximate causes of body size clines represent a further step deeper in understanding their evolution in amphibians and ultimately in vertebrates (Cvetkovic et al., 2009).

The body size variation of temperate zone bufonid toads is well documented for Bufo bufo, Bufo calamita and 
B. viridis in Europe, and for B. hemiophrys and B. woodhousii in northern America (Nevo, 1972; Hemelaar, 1988; Kellner \& Green, 1995; Castellano \& Giacoma, 1998; Eaton et al., 2005; Leskovar et al., 2006; Cvetkovic et al., 2009). All these case studies agree in that converse latitudinal Bergmann clines covering up to $3000 \mathrm{~km}$ characterize intraspecific body size variation. However, there is evidence of at least two populations at the limits of latitudinal distribution range that do not fit the general clinal pattern. In male B. bufo living at $641 \mathrm{~N}$ (northern range limit), the mean body size was considerably larger than in the more southern populations of Scandinavia (Cvetkovic et al., 2009). Similarly, in the southernmost B. calamita population of the Iberian Peninsula, the mean body size was by far smaller than that of more northern populations in Spain (Leskovar et al., 2006; Marangoni, Tejedo \& GomezMestre, 2008).

In this paper, we explore the causes of the (near) clinal body size variation in five populations of natterjack toads Epidalea (=Bufo) calamita (Laurenti, 1768) in the framework of the life-history theory. Fecundity increases with size and growth rate with ambient temperature, suggesting a complex interaction among local climate and trade-offs between delayed maturity (= increased body and clutch size) and longevity (Tejedo, 1992; Leskovar et al., 2006; Sinsch, 2008). The populations studied in Spain and Germany represent a variation of adult size from $39 \mathrm{~mm}$ to $95 \mathrm{~mm}$ (snout-vent length, SVL) and an age range from 2 to 9 years of life, a latitudinal gradient from 37 to 501 and an altitudinal gradient from sea level to $420 \mathrm{~m}$. As skeletochronological age determination also allows for the reconstruction of individual annual bone growth pattern, we were able to estimate the contribution of ontogenetic growth variation to body size at any age (Sinsch, Oromi \& Sanuy, 2007b). The aims of this study are (1) to quantify the influence of climate and elevation gradients on the age-adjusted body size variation; (2) to estimate retrospectively the relative contribution of juvenile growth to adult body size; (3) to evaluate the hypothesis that the near-clinal body size variation is a byproduct of covariation between juvenile growth rate, longevity and lifetime fecundity.

\section{Material and methods}

\section{Study areas}

A total of 313 reproductive natterjack toads E. calamita were studied at five localities, which include four habitat types, coastal sand dunes (Reserva Biologica de Donana, Andalusia, Spain), Mediterranean mountains (Navas, Andalusia, Spain), semi-arid arable plains (Balaguer and Mas de Melons, Catalonia, Spain) and flood plains of Central European streams (Urmitz, Rhineland-Palatinate, Germany). The habitat and local climate features, collection dates and numbers of reproductive adults sampled are summarized in Table 1; detailed descriptions of the localities are given in Leskovar et al. (2006), Sinsch et al. (2007b) and Marangoni et al. (2008). Climate data used for modelling are the average of a 30-year period (1971-2000) and refer to the meteorological stations of Reserva Biologica de Donana (CSIC), and Lleida-Observatorio 2, Spain and KoblenzHorchheim, Germany.

\section{Sampling procedure and skeletochronological analysis}

Following sunset, toads were collected at the local breeding ponds within 1-4 days of the spring reproduction period (Table 1). At the Urmitz study site, reproductive activity continues until August (Sinsch \& Keltsch, 2002), and a second toad sample was collected within 12 days in June. The variation in the sex ratio is due to the fact that collecting surveys were not exhaustive and thus, samples represent a random sample of the local breeding assemblage. Toads were released again in situ following sex determination, measuring of snout-vent length (SVL, to the nearest $\mathrm{mm}$ ) and toe-clipping (third toe of the right hind limb). The toes were stored in $70 \%$ ethanol at room temperature.

Laboratory protocols followed the standard methods of skeletochronology (e.g. Smirina, 1972). The samples collected in Urmitz, Balaguer and Mas de Melons were embedded in Historesin ${ }^{\mathrm{TM}}$ (Jung, Leica Microsystems Nussloch GmbH, Nussloch, Germany) and stained with

Table 1 Location, climate features and number of toads collected

\begin{tabular}{|c|c|c|c|c|c|c|}
\hline Locality & Coordinates & Altitude (m a.s.l.) & $\begin{array}{l}\text { Air temperature } \\
\text { January/July (1C) }\end{array}$ & $\begin{array}{l}\text { Annual } \\
\text { precipitation }(\mathrm{mm})\end{array}$ & Date of collection & Males/females \\
\hline Reserva Biologica & $\begin{array}{l}37100^{0} 44^{00} \mathrm{~N} \\
06130^{0} 13^{00} \mathrm{~W}\end{array}$ & 24 & $10.6 / 24.5$ & 585 & $\begin{array}{l}\text { 14.-15.III. } \\
2002\end{array}$ & $32 / 27$ \\
\hline Navas & $\begin{array}{l}37147^{0} 28^{00} \mathrm{~N} \\
06104^{0} 41^{00} \mathrm{~W}\end{array}$ & 420 & $9.6 / 25.7$ & 640 & $\begin{array}{l}3 .-6 . I I I . \\
2002\end{array}$ & $26 / 28$ \\
\hline Mas de Melons & $\begin{array}{l}41130^{0} 50^{100} \mathrm{~N} \\
00143^{0} 30^{00} \mathrm{E}\end{array}$ & 240 & $5.3 / 24.7$ & 369 & $\begin{array}{l}\text { 21.-23.IV. } \\
2004\end{array}$ & $43 / 4$ \\
\hline Balaguer & $\begin{array}{l}41146^{0} 30^{10} \mathrm{~N} \\
00146^{\circ} 50^{100} \mathrm{E}\end{array}$ & 220 & $5.3 / 24.7$ & 369 & $\begin{array}{l}1 . I V . \\
2004\end{array}$ & $34 / 14$ \\
\hline Urmitz (spring) & $\begin{array}{l}50121^{\circ} 43^{10} \mathrm{~N} \\
07135^{\circ} 48^{10} \mathrm{E}\end{array}$ & 60 & $2.7 / 19.5$ & 674 & $\begin{array}{l}\text { 19.-23.IV. } \\
2000\end{array}$ & 29/25 \\
\hline Urmitz (summer) & $\begin{array}{l}50121^{0} 43^{10} \mathrm{~N} \\
07135^{\circ} 48^{10} \mathrm{E}\end{array}$ & 60 & $2.7 / 19.5$ & 674 & $\begin{array}{l}\text { 4.-17.VI. } \\
2000\end{array}$ & $25 / 26$ \\
\hline
\end{tabular}


cresylviolet (details in Sinsch, di Tada \& Martino, 2001). Diaphysis was cross sectioned at $10 \mathrm{~mm}$ using a Jung RM2055 rotation microtome. The samples collected in Andalusia were embedded in Tissue-Tek (Sakura Finetek, Europe B.V., Alphen aan den Rijn, the Netherlands) and stained with Ehrlich's hematoxylin (details in Tejedo, Reques \& Esteban, 1997). Diaphysis was cross sectioned at $16 \mathrm{~mm}$ using a cryomicrotome (Microm International GmbH, Walldorf, Germany). A previous study demonstrated that the differences in staining procedure did not interfere with the detectability of LAGs (Sinsch et al., 2007a). Cross sections were examined light microscopically at magnifications of $\times 200$ using an Olympus BX 50 (Olympus Europa GmbH, Hamburg, Germany) or Leica DME (Leica Microsystems Ventricle GmbH, Wetzlar, Germany). High-resolution cameras Olympus DP20 (Olympus Europa GmbH) and Sony SSC-DC50AP (Sony Deutschland, Koln, Germany) were used to take digital images from those diaphysis sections in which the size of the medullar cavity was at its minimum and that of bone at its maximum.

One digital image per individual was selected for further analysis. Image files were transferred to uTHScsA ImageTool, version 3.0, and calibrated using a standard micrometer. In a first step of analysis, we recorded the presence/absence of the line of metamorphosis (LM) and of lines of arrested growth (LAGs). The number of LAGs visible in each cross section was assessed by the first author and independently by one or two co-authors. In those toads with no remnant of the LM, we checked for the potential resorption of LAGs using the method of Hemelaar (1985). In a second step, we distinguished annual growth marks (LAGs sensu stricto) from non-annual ones (irregular interruptions of the hibernal inactivity periods), using the method described in Sinsch et al. (2007b). The age of maturity was defined as the lowest age recorded in a reproductive toad of a given population. Finally, we measured the area of periosteal bone between two neighboring LAGs to the nearest $\mathrm{mm}^{2}$ in those cross sections in which the bone section was complete, to obtain an objective measure for the annual bone growth. In cases of multiple line formation within one year (common in the samples of Catalonia, Sinsch et al., 2007b), the outermost line of a group was chosen as the final growth mark of a year. The dataset obtained to model the age-size relationship included the categorical variables locality (coded 1-5), spring/summer cohort (coded 1/ 2 ), $\operatorname{sex}($ male $=1$, female $=2$ ), presence/absence of LM (coded $1 / 0$ ), presence/absence of non-annual growth marks (coded 1/0) and the quantitative variables age (number of LAGs) and SVL (mm) with $\mathrm{N}=313$ individual toads. The dataset used to analyze the growth pattern of periosteal bone included additionally the quantitative variables total bone area $\left(\mathrm{mm}^{2}\right)$ and up to eight areas of yearly bone growth (= growth rate) depending on the age of the toad. The number of observations was lower $(\mathrm{N}=280)$ because 33 incomplete bone sections allowed age determination, but not area measurement.

\section{Statistical analyses}

All variables were first tested for normality. Multifactorial analyses of covariance (ANCOVA, type III sums of squares) were used to assess the effects of age (covariate), cohort and locality on SVL and total bone area, respectively. Multiple comparisons of the least square means were based on 95\% Bonferroni confidence intervals. The age-size relationship was modelled using a general linear regression model (GLM). We tested a total of 22 variable transformations to linearize the relationship. The doublereciprocal model provided the best fit (maximum $\mathrm{R}^{2}$ ). The one-factor regression model of age (1/LAG) and size (1/SVL) was optimized using a Box-Cox transformation and complemented by successively introducing sex and locality (categorical variables). Variables were added to the model, if their corresponding coefficients were significantly different from zero (ANOVA), that is they contributed to the amount of variance explained. Further GLMs were calculated to fit the bone area-size relationship and the age-bone growth rate relationship. All GLM estimates are expressed as mean and corresponding standard error. Significance level was set at alpha $=0.05$. All calculations were based on the procedures of the program package STATGRAPHICS Centurion, version XV (STATPOINT Inc., Warrenton, VA, USA).

\section{Results}

The area between the outermost LAG and the edge of the bone from the Urmitz population was usually very small in the individuals collected during spring and considerably larger in those collected in June, indicating that toads resume growth at the beginning of the local spring breeding period. The proportion of individuals in which the LM was at least partially visible in the phalange bone sections varied significantly among the localities (ANCOVA, $\mathrm{F}_{4,301}=66.7$, PO0.00001; proportion adjusted for age as covariate, $\mathrm{F}_{1,301}=3.3, \mathrm{P}=0.0714$ ), ranging from $2.3 \%$ in Urmitz (least square mean), over 12.9 and $14.4 \%$ in Balaguer and Mas de Melons, respectively, $43.3 \%$ in Navas and $88.8 \%$ in Reserva Biologica de Donana. Resorption of the inner LAG was detected in only one out of 313 individuals (Urmitz site). The number of individuals showing non-annual growth marks also varied locally. The proportion was low in Navas (13.0\%), Urmitz (21.6\%) and Reserva Biologica de Donana (22.1\%), suggesting almost uninterrupted hibernation or aestivation, and high in Balaguer (75.0\%) and Mas de Melons (80.8\%), suggesting short-term growth periods interrupting hibernation (Sinsch et al., 2007b; Oromi, Sanuy \& Sinsch, 2010). Local age distributions differed significantly from each other (Kolmogorov-Smirnov test, all paired comparisons PO0.00001; Fig. 1). Minimum age at maturity was one LAG in the Reserva Biologica de Donana ( $n=20,33.9 \%$ of all individuals) and at Navas $(n=1,1.9 \%)$, while in all northern populations, maturity was attained at a minimum of two LAGs (Balaguer $n=11, \quad 22.9 \%$; Mas de Melons $\mathrm{n}=3$, 6.4\%; Urmitz spring cohort $\mathrm{n}=2$, $3.7 \%$; Urmitz summer cohort $n=3,5.9 \%$ ). At Navas, most first breeders pertained to the two LAG class $(n=23$, $40.7 \%)$. 

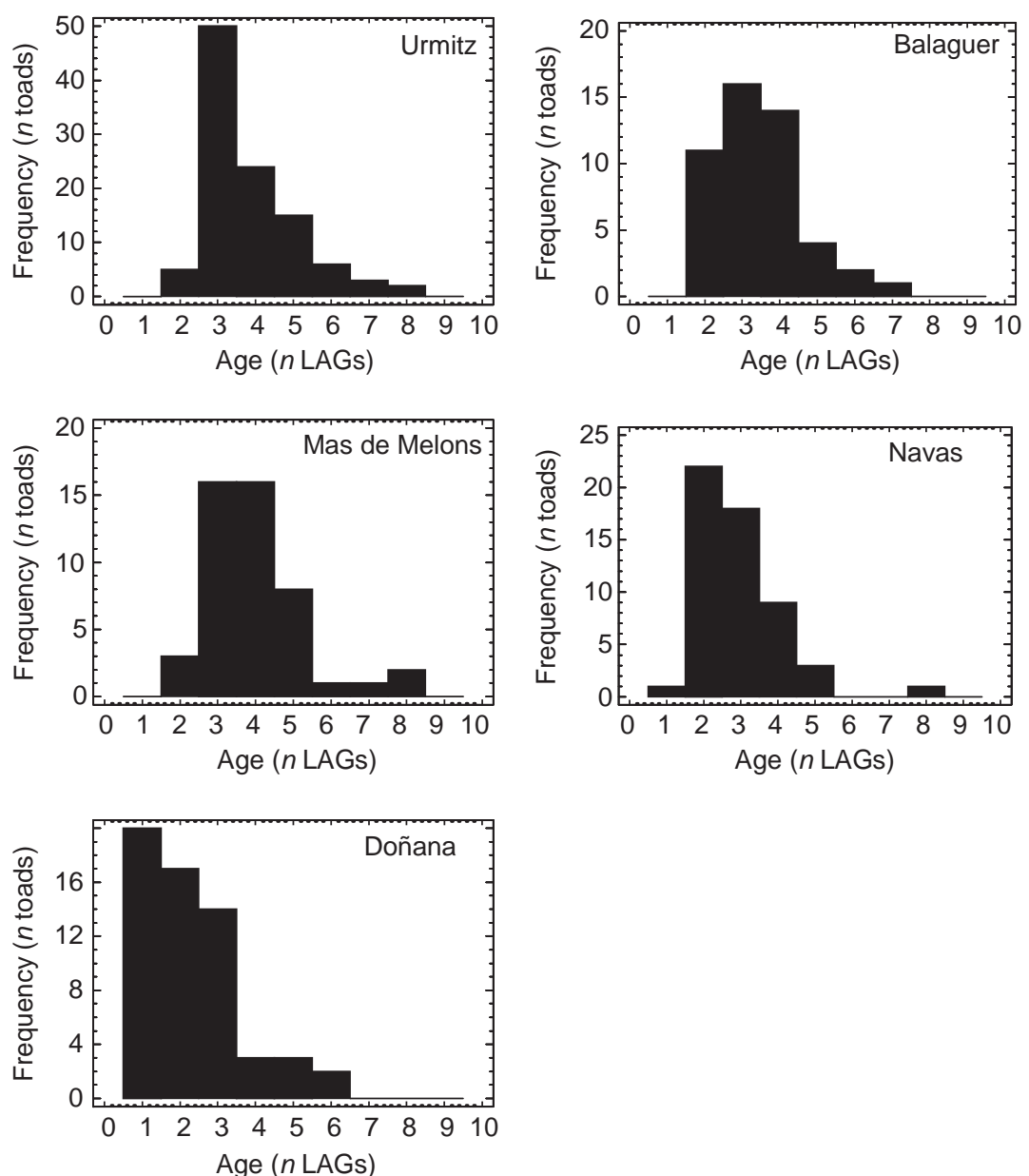

Figure 1 Age distribution of reproductive toads at the five localities studied.

\section{Local size variation predicted by age and sex}

At the Urmitz study site, SVL of adults did not differ between males and females (multifactorial ANCOVA, $\mathrm{F}_{1,104}=3.0, \mathrm{P}=0.0875$ ) and between spring/summer breeding individuals $\left(\mathrm{F}_{1,104}=1.7, \mathrm{P}=0.1965\right)$, but significantly influenced by the covariate age $\left(F_{1,104}=1687\right.$, PO0.0001). At the neighboring localities Balaguer and Mas de Melons, SVL of adults was neither influenced by sex (multifactorial ANCOVA, $\quad \mathrm{F}_{1,94}=3.8, \quad \mathrm{P}=0.0553$ ) nor by locality $\left(\mathrm{F}_{1,94}=0.01, \mathrm{P}=0.9139\right)$, but covaried significantly with age $\left(\mathrm{F}_{1,94}=5.4, \mathrm{P}=0.0224\right)$. Consequently, we reduced the six subsets of data (Table 1) to four by pooling those of the spring and summer cohorts at Urmitz and those of Balaguer and Mas de Melons, respectively.

The multifactorial ANCOVA revealed that the ageadjusted least square means of SVL (covariate age: $\mathrm{F}_{1,312}=90.8$, PO0.0001) differed considerably among the localities $\left(\mathrm{F}_{3,312}=256.9\right.$, PO0.0001), Balaguer/Mas de Melons (79.0 mm), Navas (69.4 mm), Reserva Biologica de Donana $(56.5 \mathrm{~mm})$ and Urmitz $(56.5 \mathrm{~mm})$, but not between sexes $\left(F_{1,312}=3.6, P=0.0601\right)$. However, multiple range comparison revealed that there were only three size-groups because the means of the small-sized populations did not vary among each other (PO0.05). Quantitative modelling of size variability by GLM explained $72.7 \%$ of SVL variance by the combined effects of locality, sex and age (Table 2A, Fig. 2). Age accounted for only $13.4 \%$ of the variance, sex for $0.3 \%$, whereas local differences explained $59.0 \%$. The annual increase of size in adults did not differ significantly among localities (ANOVA, $\mathrm{P}=0.1081$ ), but the intercepts of the model did (ANOVA, PO0.0001). In summary, the age- and gender-dependent body size variation of adults was low within each locality, and the major source of variation among the localities was the size at which the mostly two LAGs-old individuals became reproductive, that is the size achieved during the juvenile stage and then population divergence in adult size is a function of variation in juvenile growth rates.

\section{Patterns of annual bone growth}

At the Urmitz study site, the annual bone growth rate of toads that reproduced during spring differed significantly from that of individuals that reproduced during summer at the first (multifactor ANCOVA; $\mathrm{F}_{1,100}=6.9, \mathrm{P}=0.0102$ ) 
Table 2 GLM models to predict size (SVL) (A) or by phalange bone size (C) by age and local factors

\begin{tabular}{|c|c|c|c|c|c|}
\hline Model coefficient & Estimate T standard error & Wilk's lambda & F-value & Significance & Contribution to $\mathrm{R}^{2}$ \\
\hline \multicolumn{6}{|c|}{ (A) Box-Cox transformation applied power: -1.36311} \\
\hline Constant & 0.98698 T 0.000234 & & & & \\
\hline 1/age & $0.003416 \mathrm{~T} 0.000543$ & 0.8858 & 39.4 & Po0.00001 & $13.4 \%$ \\
\hline \multicolumn{6}{|l|}{ Locality } \\
\hline $1 / 4$ & $0.002129 \mathrm{~T} 0.000157$ & 0.3157 & 221.8 & Po0.00001 & $59.0 \%$ \\
\hline $2 / 4$ & $-0.003407 \mathrm{~T} 0.0001628$ & & & & \\
\hline $3 / 4$ & -0.00076 T 0.000181 & & & & \\
\hline Sex & $0.000207 \mathrm{~T} 0.000096$ & 0.9850 & 4.7 & $P=0.0316$ & $0.3 \%$ \\
\hline Total $R^{2}$ (adjusted for degrees of freedom) & & & & & $72.7 \%$ \\
\hline \multicolumn{6}{|c|}{ (B) Box-Cox transformation applied power: 0.193897} \\
\hline Constant & 0.893239 T 0.000197 & & & & \\
\hline 1/bone area & $783.34 \mathrm{~T} 33.10$ & 0.3261 & 560.2 & Po0.00001 & $80.0 \%$ \\
\hline Region & $0.000674 \mathrm{~T} 0.000118$ & 0.8926 & 32.6 & Po0.00001 & $1.1 \%$ \\
\hline Total $R^{2}$ (adjusted for degrees of freedom) & & & & & $81.1 \%$ \\
\hline
\end{tabular}

Best fit (maximum $\mathrm{R}^{2}$ ): double reciprocal model. Model $\mathrm{A}$ differs from $\mathrm{B}$ by the introduction of local habitat and climate features as categorical or quantitative variables. Numerical range of variables: age, 1-8 LAGs; sex, male =1, female = -1 ; locality, $1=$ Urmitz, $2=$ Balaguer/Mas de Melons, 3=Navas, 4 = Reserva Biologica de Doñana; region: 1=Urmitz/Navas/Reserva Biologica de Doñana, 2=Balaguer/Mas de Melons.
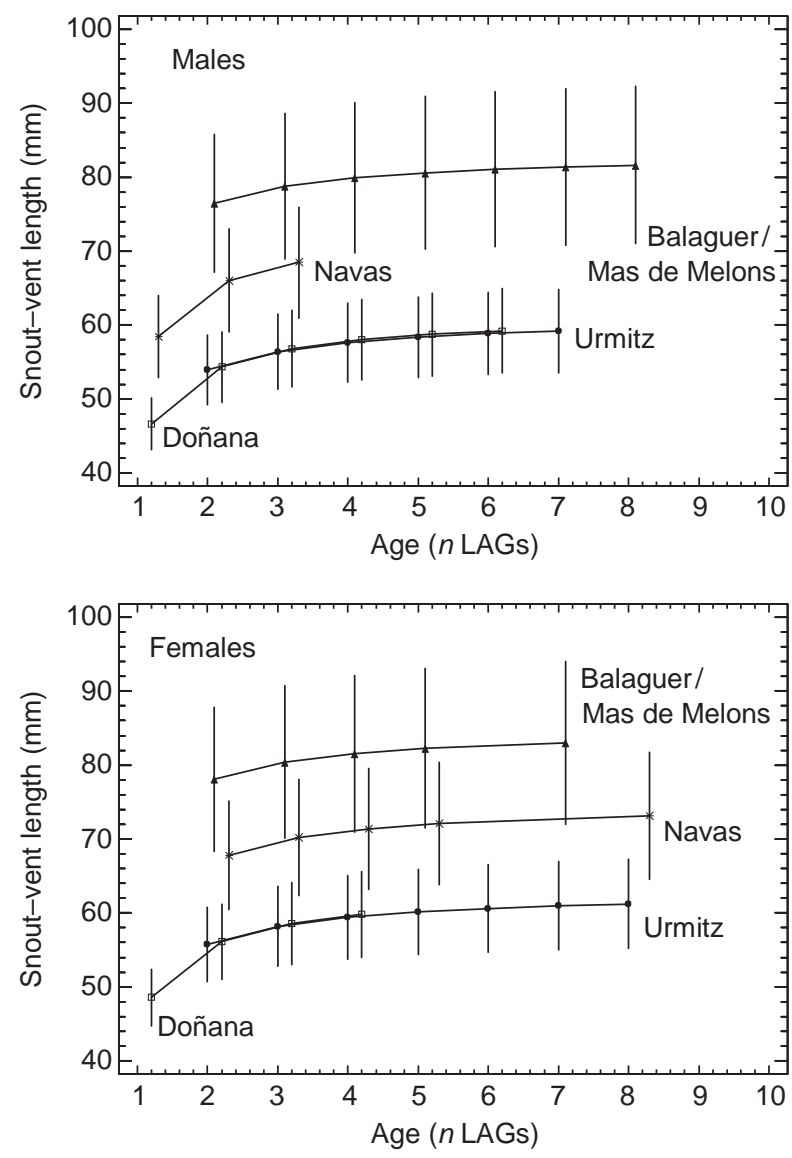

Figure 2 Age-size relationship for the studied populations (generalized linear regression models). (a) Males; (b) Females. Symbols represent the SVL estimates (least square means) and bars show the corresponding $95 \%$ confidence interval.

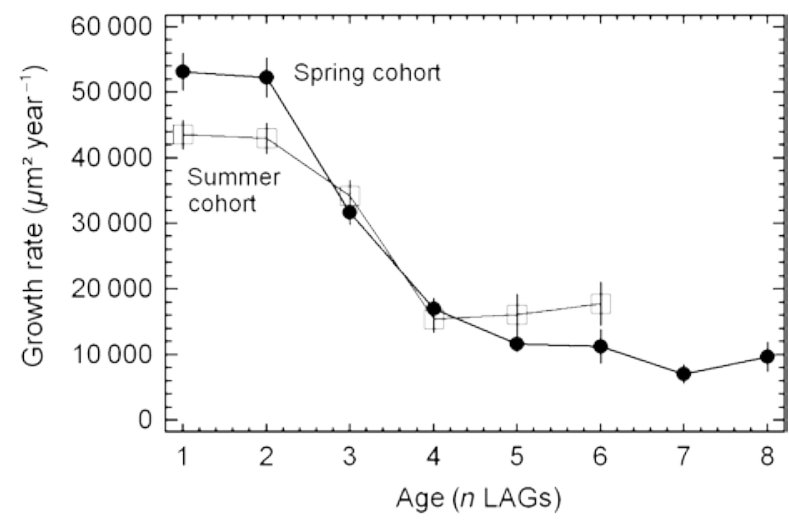

Figure 3 Annual growth rate of periosteal bone of toads reproducing in spring $(\mathrm{N}=52)$ or in summer $(\mathrm{N}=49)$ at the Urmitz study site. Data are given as least square means and the corresponding $95 \%$ confidence interval. Statistical details are given in the text.

and second year of life $\left(\mathrm{F}_{1,100}=5.2, \mathrm{P}=0.0252\right)$, respectively, whereas sex did not influence the growth rate in any year $\left(\mathrm{F}_{1,100}\right.$, P40.05; Fig. 3). Age at the time of capture (multifactor ANCOVA; $\mathrm{F}_{1,100}, \mathrm{P}$ 40.05) did not covary with the annual bone growth rate, suggesting that periosteal bone does not condense with increasing age in natterjack toads. Growth rates were significantly smaller in the summer cohort (least square means: $43272 \mathrm{~mm}^{2}$ during the first year; $43362 \mathrm{~mm}^{2}$ during the second year) than in the spring cohort (53 $435 \mathrm{~mm}^{2}$ and $51581 \mathrm{~mm}^{2}$, respectively). Consequently, we used only the spring cohort of Urmitz for further comparisons with the Spanish populations, which consist exclusively of spring breeders.

At any year of life, the average bone growth rate varied significantly among localities, but not between males and 


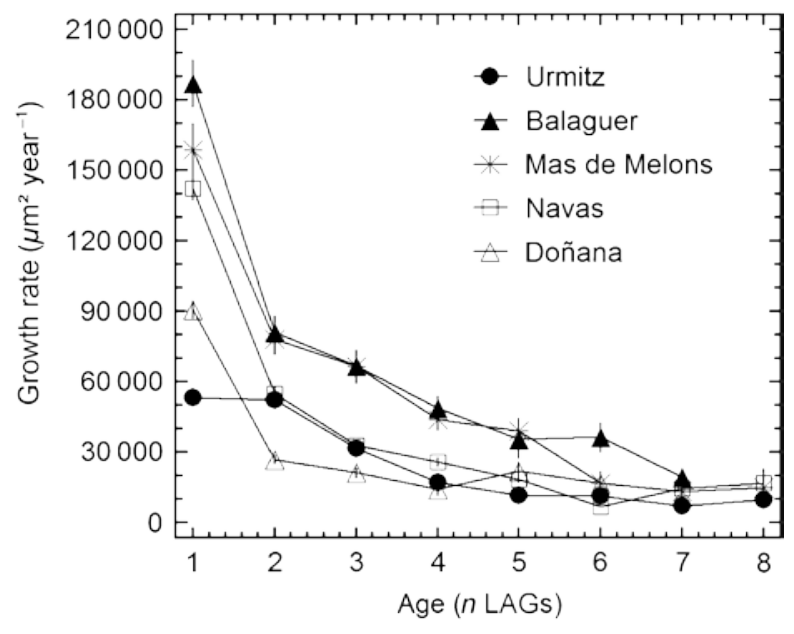

Figure 4 Least square means and the corresponding $95 \%$ confidence interval for the lifetime growth pattern of periosteal bone in five localities. Statistical details are given in the text.

females and independent of age at capture, as revealed by multifactorial ANCOVAs (Fig. 4). During the first year of life (ANCOVA; $\mathrm{F}_{4,230}=84.2$, PO0.0001), bone growth differed significantly among all the localities (multiple range test; Po 0.05): Balaguer (least square mean: 191925T $6701 \mathrm{~mm}^{2}$ ), Mas de Melons (168 196 T $7696 \mathrm{~mm}^{2}$ ), Navas $\left(138456 \mathrm{~T} 5365 \mathrm{~mm}^{2}\right)$, Reserva Biologica de Donana $\left(83117 \mathrm{~T} 5471 \mathrm{~mm}^{2}\right)$ and Urmitz (61 100 T $\left.5749 \mathrm{~mm}^{2}\right)$. During the second year of life ife (ANCOVA; $F_{4,206}=22.6$, PO0.0001), bone grew most in the Catalonian populations forming a homogeneous group (multiple range test; Po0.05), followed by a group formed by the Navas and Urmitz populations, and by the Donana population. During the subsequent years of life, Urmitz and the Andalusian populations formed a homogeneous group with respect to annual bone growth (multiple range test; PO0.05), whereas the Catalonian population continued to exhibit significantly greater growth rates.

\section{Retrospective size prediction by bone area}

The GLM of the bone area-adult size relationship explained $81.1 \%$ of SVL variance by total bone area as quantitative variable and of region as a categorical variable, which led to a small, but significant contribution due to the difference among the Catalonian populations on the one hand and those of Andalusia and Urmitz on the other (Table 2B, Fig. 5). The variables sex and age did not increase $R^{2}$ significantly. The GLM, therefore, allows for a retrospective estimation of SVL at any stage of the lifetime of a natterjack toad calculating the corresponding SVL to the bone area bordered by each LAG.

The translation of bone growth pattern into annual SVL gain revealed significant differences among all the populations with respect to SVL achieved before the formation of the first LAG and between the populations of the Iberian Peninsula and those from Germany for the second and third
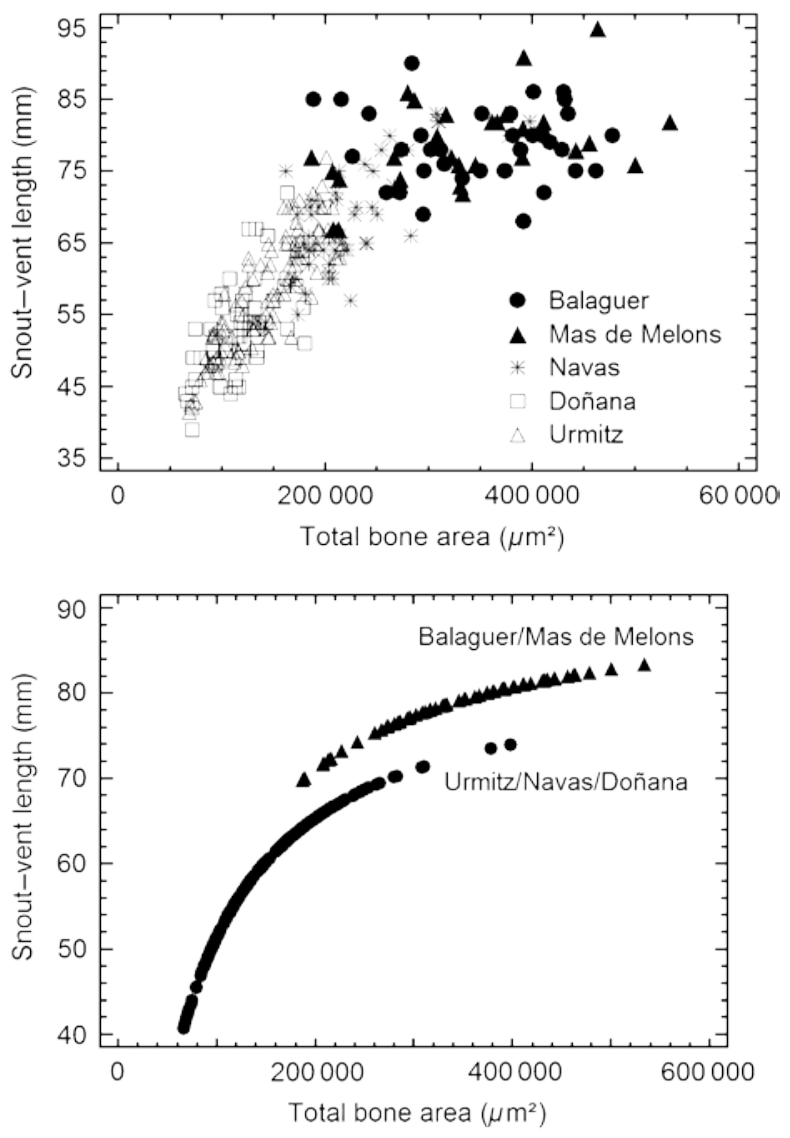

Figure 5 Bone size-SVL relationship. (a) Scatter plot of 280 individuals; (b) GLM model for two groups of localities; coefficients are given in Table 2, and symbols represent individual estimates.

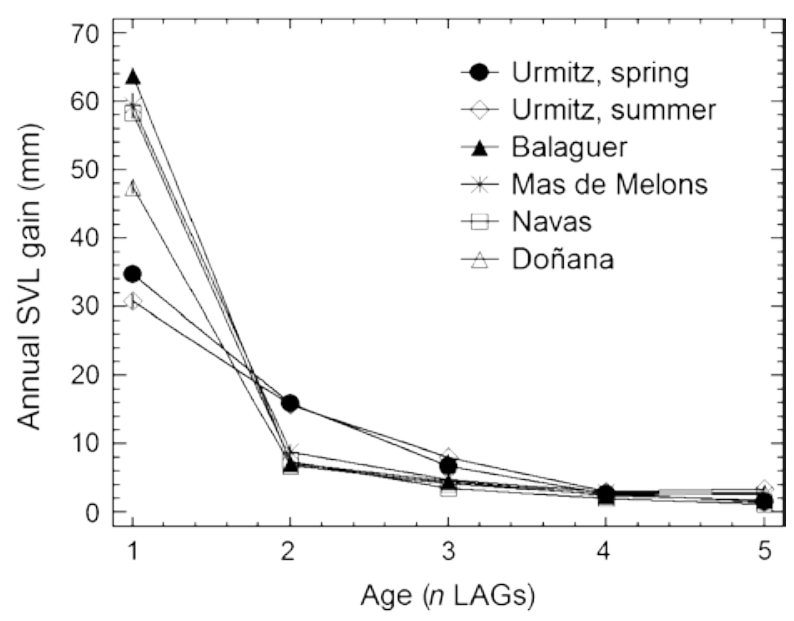

Figure 6 Least square means of annual SVL gain and the corresponding $95 \%$ confidence interval estimated from the bone growth pattern of toads originating from five localities. At the Urmitz site, the toads breeding in spring are distinguished from those breeding during summer. 
LAGs (Fig. 6). Except for the first year of life, Spanish populations did not differ in their growth pattern (Fig. 6). While the average first year SVL varied between $47.5 \mathrm{~mm}$ (Reserva Biologica de Donana) and $63.7 \mathrm{~mm}$ (Balaguer), second year SVL gain declined sharply at all localities to $7.4 \mathrm{~T} 1.2 \mathrm{~mm}$ and annual SVL gain remained unchanged at $2.5 \mathrm{~T} 1.0 \mathrm{~mm}$ from the fourth year onwards (Fig. 6). The first year size at the German locality differed significantly between the members of the spring and summer cohorts and the average SVL was about $14 \mathrm{~mm}$ smaller than that of the small-sized Spanish population in Donana (Table 3). Following the first year of life, the growth pattern of the two cohorts was undistinguishable, but second and third year SVL gain $(15.9 \mathrm{~mm}$ and $7.4 \mathrm{~mm})$ was significantly greater than in the Spanish populations (ANOVA, PO0.001). From the fourth year onwards, the growth pattern of all populations converged to a homogeneous annual SVL gain of about $2.5 \mathrm{~mm}$.

\section{Discussion}

Size variations among conspecific amphibian populations exposed to environmental gradients are probably driven by different proximate causes than those mentioned to explain latitudinal size clines at the interspecific level in Amphibia (Olalla-Tarraga \& Rodriguez, 2007; Gaston, 2008; Cvetkovic et al., 2009). The broad-scale geographical pattern of body size for the European amphibian fauna seems to be compatible with a Bergmann cline, if the data analysis is based on the maximum SVL of each anuran species (OlallaTarraga \& Rodriguez, 2007). However, the validity of this approach is doubtful because it neglects the intraspecific size variation in species such as B. bufo, B. calamita and R. temporaria, which follows roughly a converse Bergmann cline (Miaud et al., 1999; Laugen et al., 2005; Leskovar et al., 2006; Cvetkovic et al., 2009; this study). Basic to a better understanding of size variation in Amphibia as a group is consequently the analysis of the proximate causes of intraspecific size variation in the framework of the lifehistory theory (Angilletta et al., 2004; Adams \& Church, 2008). The large adult size obtained by delaying sexual maturity provides the benefit of increased clutch size, but may be associated with costs such as increased juvenile and adult mortality. The life-history theory predicts that delayed maturity and associated size gain should be selected for if lifetime fecundity is increased.

The lifetime growth pattern of European toads includes a short aquatic larval period in which usually less than $20 \%$ of the adult size is attained and a terrestrial period with indeterminate growth that declines at sexual maturity (Werner, 1986; Hemelaar, 1988). In B. calamita, metamorph size ranges from 4 to $12 \mathrm{~mm}$ SVL, covarying with larval density and interspecific competition in the breeding pond (Goater, 1994; Gomez-Mestre \& Tejedo, 2002; Sinsch, 2008). The populations studied do not depart from this rule, with the average metamorph size ranging from 6 to $9 \mathrm{~mm}$ (Sinsch, Hofer \& Keltsch, 1999; N. Oromi, M. Tejedo \& F. Marangoni, unpub. obs.). Thus, body size variation is mainly a consequence of the terrestrial growth period. Unlike in B. viridis, local genetic adaptations appear to be a negligible source of size variation in B. calamita because the populations in Andalusia do not exhibit significant genetic divergence but close to maximum differences in adult size (Castellano \& Giacoma, 1998; Marangoni, 2006; this study).

\section{Environmental causes of phenotypic size plasticity}

There are several potential determinants of phenotypic plasticity in the adult body size of amphibians, for example age and associated variation of growth rate, food availability and temperature-dependent limitations of annual growth periods (e.g. Jørgensen, 1992; Gramapurohit, Shanbhag \& Saidapur, 2004). The GLM model describing adult growth of natterjacks indicates that the annual growth rates are similar (about $2.5 \mathrm{~mm}$ year $^{-1}$ ) in all populations and thus independent of latitude. The independence of the growth rate from altitude, however, refers exclusively to the studied lowland range of up to $420 \mathrm{~m}$ a.s.l., while natterjacks inhabit altitudes of up to $2540 \mathrm{~m}$ a.s.l. in the Sierra Nevada, Spain (Sinsch, 2008). Preliminary data indeed suggest the presence of a converse Bergmann cline in populations of the Sierra de Gredos, Spain (Oromi, study in progress).

In contrast, the intercepts of the GLM, that is the size of the first breeders, do distinguish among the populations, suggesting that the environmental impact on subadult terrestrial growth period is the primary source of size variation among natterjack populations. More precisely, it is the first-year growth that yields the difference, as

Table 3 Estimated SVL variation at the end of the first terrestrial growth period (one LAG) among the studied toad population

\begin{tabular}{|c|c|c|c|c|}
\hline Locality & $\begin{array}{l}\text { Average SVL } \\
(\mathrm{T} \mathrm{SE})(\mathrm{mm})\end{array}$ & $\begin{array}{l}\text { Duration of first year aboveground } \\
\text { feeding activity (month) }\end{array}$ & $\begin{array}{l}\text { Duration of first year inactivity } \\
\text { period (month) }\end{array}$ & $\begin{array}{l}\text { Feeding/growth during } \\
\text { aestivation/hibernation }\end{array}$ \\
\hline $\begin{array}{l}\text { Reserva Biologica de } \\
\text { Doñana }\end{array}$ & $47.5 \mathrm{~T} 1.0$ & $4-6$ & c. 4 (aestivation) & No \\
\hline Navas & 58.3 T 1.0 & $4-6$ & c. 4 (aestivation) & Unknown \\
\hline Mas de Melons & 59.7 T 1.4 & $4-6$ & c. 4 (aestivation+hibernation) & Yes \\
\hline Balaguer Urmitz & $63.7 \mathrm{~T} 1.2$ & $4-6$ & c. 4 (aestivation+hibernation) & Yes \\
\hline (spring) Urmitz & $34.8 \mathrm{~T} 1.1$ & $3-4$ & c. 6 (hibernation) & No \\
\hline (summer) & $30.8 \mathrm{~T} 1.1$ & $2-3$ & c. 6 (hibernation) & No \\
\hline
\end{tabular}

All SVL estimates differ significantly from each other (ANOVA, multiple-range test; Po0.05). 
demonstrated by the retrospective SVL estimation. Within eventual determinants of juvenile growth, food availability does not seem to constrain the terrestrial growth of natterjacks at any site studied so far (review: Sinsch, 2008; Urmitz: Leskovar, Wagner \& Sinsch, 2004). Therefore, we first concentrate on the environmental factors modulating and limiting the duration and intensity of the first-year growth period, and then focus on the subsequent geographical variation of life-history traits such as age and size at maturity and their evolutionary significance.

In the temperate zone, the growth rates vary seasonally, determined by the varying environmental temperatures (i.e. duration of activity period) and food supply (Jørgensen, 1992). The growth rates of metamorphs at Urmitz, Germany, provide the test case, as temperature and the nonlimiting food supply are identical for the spring and summer cohort, but the latter has a shorter activity period before hibernation, resulting in a c. $4 \mathrm{~mm}$ lower SVL (Sinsch et al., 1999; Leskovar et al., 2004; Table 3). The subsequent inactivity period of juveniles burrowed in sand does not allow further growth partially due to inherent growth rhythms demonstrated under controlled conditions and the absence of food in the hibernacula (Leskovar \& Sinsch, 2001). Thus, the length of the activity period explains entirely the firstyear size variation between the members of the spring and summer cohorts in Germany.

Although adults of the Urmitz and the Donana population are similar-sized, first-year individuals grew about $12 \mathrm{~mm}$ larger in Spain, demonstrating different lifetime growth regimes at the two sites. The most likely cause for the faster metamorph growth is ambient temperature, which allows higher metabolic rates and better food utilization in Spain (Jørgensen, 1992). The duration of the aboveground activity period appears to be similar, in Germany ended by hibernation, in Andalusia by aestivation (Table 3). As inactive individuals are burrowed in the sandy soil at both sites, we do not expect the Donana toads to feed and to grow during aestivation, but this hypothesis remains to be proven. If correct, size variation between first-year individuals of the Urmitz and the Donana population is a direct temperature effect, which is compensated for adult size by the increased second-year growth of the still immature toads in Urmitz.

The first-year individuals of the remaining three Spanish populations were another $12-15 \mathrm{~mm}$ larger than the Donana toads, although the local climate is similar, but moderately colder during winter. Consequently, the duration of aboveground activity is also similar, but the microhabitats used for aestivation (all localities) and hibernation (Balaguer/ Mas de Melons) are rabbit holes, rock fissures and crevices because the absence of sandy soils prevents the toads from actively burrowing as in Urmitz and Donana (Oromi et al., 2010). Radio-telemetric monitoring of adults at Mas de Melons and several short bone growth periods during winter suggest that the shelter microclimate allows locomotor activity including foraging underground (Sinsch et al., 2007b; Oromi et al., 2010). Similar information is not yet available for the Navas site. Still, it seems reasonable to assume that the different microhabitats used for hibernation and/or aestivation are the proximate causes for the size difference of juveniles. Cavity systems also provide shelter for invertebrate prey, while the small-volume burrows in sand without connection to the ground surface do not. Thus, the period that toads spend underground can be considered as an extension of the feeding period in Balaguer and Mas de Melons, and additional growth is achieved in comparison with the burrowed soil of the Donana population. However, field reciprocal transplant experiments on the Spanish spadefoot toad, Pelobates cultripes, between Donana and Navas environments show reduced growth in the sandy environment for all the populations, thus suggesting a role of environmentally induced plasticity in the growth rates across environments that may explain the unexpected lower growth of the Donana populations (M. Tejedo \& F. Marangoni, unpubl. data). Reduced size has also been observed in other amphibian species inhabiting the Donana region (Diaz-Paniagua, Mateo \& Andreu, 1996; Diaz-Paniagua \& Mateo, 1999).

In summary, the geographical body size variation in B. calamita populations is probably the result of interactions among latitudinal temperature effects, microhabitat choice for hibernation/aestivation and habitat constraints to growth determining a pattern to some extent compatible to a converse Bergmann cline. This is in agreement with the latitudinal trend observed in B. bufo (Cvetkovic et al., 2009) and supports the idea that amphibians do not follow Bergmann's rule (Ashton, 2002b; Adams \& Church, 2008). The proximate causes identified act mainly on juveniles during their first year of life, which represents the sensitive period for fast growth in anurans (Jørgensen, 1992).

\section{Fitness consequences of body size variation on lifetime fecundity}

The youngest first breeders were 1-year-old individuals (about one-third of the Donana population), indicating that the threshold size for maturity is about $40 \mathrm{~mm} \mathrm{SVL}$ in B. calamita. This size is reached and often considerably passed in all populations from the Iberian Peninsula during the first year of life, suggesting that natterjacks are sexually mature at the beginning of the second year. The sharp decline of bone growth during the second year is another indicator of previous sexual maturation (Hemelaar, 1988). Still, there was an increasing tendency from south to north to postpone first reproduction to the third (two LAGs) or the fourth year (three LAGs). The benefit is an SVL increase of $7-10 \mathrm{~mm}$ on average, allowing for a significantly larger clutch size than in first breeders at the minimum SVL (Tejedo, 1992). In Germany, first-year growth is too low to attain sexual maturity, and therefore, the growth rate remains high during the second year in which individuals pass the threshold size similar to the growth pattern in B. bufo (Hemelaar, 1988). Again, most adults postpone reproduction for at least 1 year.

In natterjacks, size at first reproduction and age at maturity are not tightly coupled. Delayed reproduction may be selected for if fitness increases by the SVL-associated 
fecundity gain and lifetime fecundity is optimized, that is the product of clutch size and potential reproductive lifespan (longevity - age at first reproduction). The potential reproductive lifespan of females decreases from north to south: 6-5 years (spring/summer cohort) in Urmitz to 3-4 years in Catalonia and Andalusia (Leskovar et al., 2006; this study). Because the average clutch size follows a converse gradient, lifetime fecundity is probably similar in most of the geographical range (Sinsch, 2008). The southernmost Donana population is the exception from the rule, with small clutches similar to those in Germany and a low potential reproductive lifespan as in the rest of the Iberian Peninsula. Considering the harsh environmental condition at this site and short longevity, selection should favor early reproduction at small SVL (Marangoni, 2006; Marangoni et al., 2008). Applying a life-history perspective, latitudinal body size variation among B. calamita populations, and perhaps also that of other amphibians species, is the evolutionary byproduct of optimized lifetime fecundity.

\section{Acknowledgments}

The permissions for field studies and handling of the toads were issued by the Struktur und Genehmigungsbehorde Nord, Koblenz, Germany, the Departament de Medi Ambient, Generalitat de Catalunya and the Consejeria de Medio Ambiente de la Junta de Andalucia and the Reserva Biologica de Donana, Spain. This work was supported by the grant CGL2004-01872/BOS from Direccion General de Investigacion Cientıfica y Tecnica conceded to $\mathrm{M}$. Tejedo. T.J.C. Beebee and an anonymous reviewer provided useful comments on an earlier draft of the paper.

\section{References}

Adams, D.C. \& Church, J.O. (2008). Amphibians do not follow Bergmann's rule. Evolution 62, 413-420.

Angilletta, M.J., Niewiarowski, P.H., Dunham, A.E., Leache, A.D. \& Porter, W.P. (2004). Bergmann's clines in ectotherms: illustrating a life-history perspective with sceloporine lizards. Am. Nat. 164, E168-E183.

Ashton, K.G. (2002a). Patterns of within-species body size variation of birds: strong evidence for Bergmann's rule. Global Ecol. Biogeogr. 11, 505-523.

Ashton, K.G. (2002b). Do amphibians follow Bergmann's rule? Can. J. Zool. 80, 708-716.

Bergmann, C. (1847). Uber die Verhaltnisse der Warmeokonomie der Thiere zu ihrer Grosse. Göttinger Studien 1, 595-708.

Castellano, S. \& Giacoma, C. (1998). Morphological variation of the green toad, Bufo viridis, in Italy: a test of causation. J. Herpetol. 32, 540-550.

Cvetkovic, D., Tomasevic, N., Ficetola, G.F., CrnobrnjaIsailovic, J. \& Miaud, C. (2009). Bergmann's rule in amphibians: combining demographic and ecological parameters to explain body size variation among populations in the common toad Bufo bufo. J. Zool. Syst. Evol. Res. 47, 171-180.

Diaz-Paniagua, C. \& Mateo, J.A. (1999). Geographic variation in body size and life-history traits in Bosca's newt (Triturus boscai). Herpetol. J. 9, 21-27.

Diaz-Paniagua, C., Mateo, J.A. \& Andreu, A.C. (1996). Age and size structure of populations of small marbled newts (Triturus marmoratus pygmaeus) from Donana National Park (SW Spain). A case of dwarfism among dwarfs. J. Zool. 239, 83-92.

Eaton, B., Paszkowski, C.A., Kristensen, K. \& Hiltz, M. (2005). Life-history variation among populations of Canadian Toads in Alberta, Canada. Can. J. Zool. 83, 1421-1430.

Elmberg, J. (1991). Ovarian cyclicity and fecundity in boreal common frogs Rana temporaria L. along a climatic gradient. Funct. Ecol. 5, 340-350.

Freckleton, R.P., Harvey, P.H. \& Pagel, M. (2003). Bergmann's rule and body size in mammals. Am. Nat. 161, 821-825.

Gaston, K.J. (2008). Ecogeographical rules: elements of a synthesis. J. Biogeogr. 35, 483-500.

Goater, C.P. (1994). Growth and survival of postmetamorphic toads: interactions among larval history, density, and parasitism. Ecology 75, 2264-2274.

Gomez-Mestre, I. \& Tejedo, M. (2002). Geographic variation in asymmetric competition: a case study with two larval anuran species. Ecology 83, 2102-2111.

Gramapurohit, N.P., Shanbhag, B.A. \& Saidapur, S.K. (2004). Growth, sexual maturation and body size dimorphism in the Indian bullfrog, Hoplobatrachus tigerinus (Daudin). Herpetologica 60, 414-419.

Hemelaar, A.M.S. (1985). An improved method to estimate the number of year rings resorbed in phalanges of Bufo bufo (L.) and its application to populations from different latitudes and altitudes. Amphibia-Reptilia 6, 323-342.

Hemelaar, A.M.S. (1988). Age, growth and other population characteristics of Bufo bufo from different latitudes and altitudes. J. Herpetol. 22, 369-388.

Jørgensen, C.B. (1992). Growth and reproduction. In Environmental physiology of the amphibians: 439-466. Feder, M.E. \& Burggren, W.W. (Eds). Chicago: The University of Chicago Press.

Kellner, A. \& Green, D.M. (1995). Age structure and age at maturity in Fowler's toads, Bufo woodhousii fowleri, at their northern range limit. J. Herpetol. 29, 485-489.

Krizmanic, I., Vukov, T.D. \& Kalezic, M.L. (2005). Bergmann's rule is size-related in European newts (Triturus). Herpetol. J. 15, 205-206.

Laugen, A.T., Laurila, A., Jonsson, K.I., Soderman, F. \& Merila, J. (2005). Do common frogs (Rana temporaria) follow Bergmann's rule? Evol. Ecol. Res. 7, 717-731.

Leskovar, C., Oromi, N., Sanuy, D. \& Sinsch, U. (2006). Demographic life history traits of reproductive natterjack toads (Bufo calamita) vary between northern and southern latitudes. Amphibia-Reptilia 27, 365-375. 
Leskovar, C. \& Sinsch, U. (2001). Hibernation behaviour of radiotracked natterjack toads Bufo calamita and green toads Bufo viridis. Biota (Suppl.) 2, 33-34.

Leskovar, C., Wagner, T. \& Sinsch, U. (2004). Saisonale Dynamik des Nahrungsspektrums syntoper Kreuz- (Bufo calamita) und Wechselkroten-Populationen (B. viridis) in einem rheinischen Auskiesungsgebiet. Z. Feldherpetol. 11, 83-103.

Marangoni, F. (2006). Variación clinal en el tamaño del cuerpo a escala microgeográfica en dos especies de anuros (Pelobates cultripes y Bufo calamita). PhD Thesis, Universidad de Sevilla, Sevilla.

Marangoni, F., Tejedo, M. \& Gomez-Mestre, I. (2008). Extreme reduction in body size and reproductive output associated with sandy substrates in two anuran species. Amphibia-Reptilia 29, 541-553.

Meiri, S. \& Dayan, T. (2003). On the validity of Bergmann's rule. J. Biogeogr. 30, 331-351.

Miaud, C., Guyetant, R. \& Elmberg, J. (1999). Variations in life-history traits in the common frog Rana temporaria (AmphibiaAnura): a literature review and new data from the French Alps. J. Zool. 249, 61-73.

Nevo, E. (1972). Climatic adaptation in size of the green-toad, Bufo viridis. Isr. J. Med. Sci. 8, 1010 (abstract).

Olalla-Tarraga, M.A. \& Rodriguez, M.A. (2007). Energy and interspecific body size patterns of amphibian faunas in Europe and North America: anurans follow Bergmann's rule, urodeles its converse. Global Ecol. Biogeogr. 16, 606-617.

Oromi, N., Sanuy, D. \& Sinsch, U. (2010). Thermal ecology of natterjack toads (Bufo calamita) in a semi-arid landscape. J. Therm. Biol. 35, 34-40.

Ray, C. (1960). The application of Bergmann's rule and Allen's rule to the poikilotherms. J. Morphol. 106, 85109.
Sinsch, U. (2008). Bufo calamita Laurenti, 1768 - Kreuzkrote. In Handbuch der Amphibien und Reptilien Europas: 339-413. Grossenbacher, K. (Ed.). Wiesbaden: Aula Verlag.

Sinsch, U., Hofer, S. \& Keltsch, M. (1999). Syntopes Vorkommen von B. calamita, B. viridis und Bufo bufo in einem rheinischen Auskiesungsgebiet. Z. Feldherpetol. 6, 43-64.

Sinsch, U. \& Keltsch, M. (2002). Die Fekunditat von Kreuzkroten (Bufo calamita) und Wechselkroten (B. viridis) in einem rheinischen Auskiesungsgebiet. Z. Feldherpetol. 9, 1-15.

Sinsch, U., Leskovar, C., Drobig, A., Konig, A. \& Grosse, W.R. (2007a). Life history traits in green toad (Bufo viridis) population: indicators of habitat quality. Can. J. Zool. 85, 665-673.

Sinsch, U., Oromi, N. \& Sanuy, D. (2007b). Growth marks in natterjack toad (Bufo calamita) bones: histological correlates of hibernation and aestivation periods. Herpetol. J. 17, 129-137.

Sinsch, U., di Tada, I.E. \& Martino, A.L. (2001). Longevity, demography and sex-specific growth of the Pampa de Achala Toad, Bufo achalensis CEI, 1972. Stud. Neotrop. Fauna and Environ. 36, 95-104.

Smirina, E.M. (1972). Annual layers in bones of Rana temporaria. Zoologichesky Zh. 51, 1529-1534.

Tejedo, M. (1992). Effects of body size and timing of reproduction on reproductive success in female natterjack toads (Bufo calamita). J. Zool. 228, 545-555.

Tejedo, M., Reques, R. \& Esteban, M. (1997). Actual and osteochronological estimated age of natterjack toads (Bufo calamita). Herpetol. J. 7, 81-82.

Werner, E.E. (1986). Amphibian metamorphosis: growth rate, predation risk, and the optimal size at transformation. Am. Nat. 128, 319-341. 